\title{
Clinical and surgical treatment of secondary orbital abscess in ethmoidal sinusitis
}

\author{
Tratamento clínico e cirúrgico de abscesso \\ orbital secundário a sinusite etmoidal
}

Abelardo de Souza Couto Junior¹, Rafael Siqueira Barbosa², José Fábio de Oliveira Miranda ${ }^{3}$

\begin{abstract}
The authors report the case of na eighteen years old patient with a clinical picture of orbital abscess caused by ethmoid sinusitis. The decision for surgical intervention results from correlation between clinical findings and from the image diagnosis.

Keywords: Abscess/surgery;Ethmoid sinusitis/surgery; Orbit/radiography;Tomography, x-ray computed;Adult; Female; Case reports

\section{ResUMo}

Relato de um caso de uma paciente de 18 anos com um quadro clinico de abscesso orbital causado por sinusite etmoidal. A decisão pela intervenção cirúrgica resultou da correlação entre achados clínicos e do diagnóstico dos exames de imagem.

Descritores: Abscesso/cirurgia; Sinusite etmoidal/cirurgia; Órbita/radiografia; Tomografia computadorizada por raios x; Adulto; Feminino; Relatos de casos
\end{abstract}

\footnotetext{
'Faculdade de Medicina de Valença (FMV) - Rio de Janeiro (RJ), and Benjamin Constant's Federal Institute - Rio de Janeiro (RJ), Brazil;

${ }^{2}$ Hospital de Olhos de Niterói - Niterói - Rio de Janeiro (RJ), Brazil;

${ }^{3}$ Faculdade de Medicina de Valença - FMV - Rio de Janeiro (RJ), Brazil.

Interest conflict - None
}

Recebido para publicação em 10/5/2011 - Aceito para publicação em 4/12/2011 


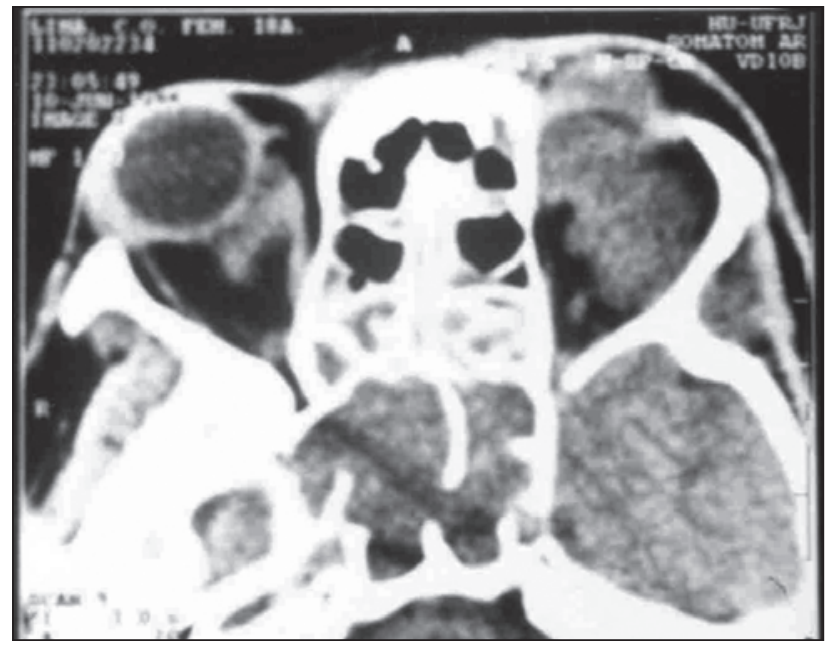

Figure 1: Orbital CT; axial cut demonstrating sub-periostal orbital abscess at left and right with etmoidal sinus invasion

\section{INTRODUCTION}

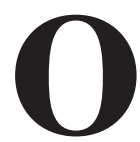
rbital cellulitis is na acute Picture of quick evolution and represents a real medical emergency ${ }^{(1)}$. The clinical and visual prognostics depend on strict association of the clinical picture and the imaged diagnostic procedures, aiming at the Best therapeutic decision.

The causes for orbital cellulitis include infection of adjacent ( dacryocistilis ) structures, as well as posttraumatic, post-surgical ( strabisms, orbital surgeries, etc ) causes and are associated with paranasal sinus infection. The latter is the most common reason and the ethmoidal sinus is most frequently affected ${ }^{(2,3)}$.

Among imaged diagnoses, we point out both the standardized ultrasound ( USG ) and the orbital computerized tomography ( CT ) as of most importance for surgical planning ${ }^{(2,4)}$.

\section{Report on clinical case}

An eighteen years old female patient, Born and coming from Rio de Janeiro, presenting a picture of intense proptosis in $\mathrm{OE}$, associated with quemosis and ocular pain, initial normal neuro - ophthalmological examination with visual acuity in OE 20/30 and in OD a discrete hyperemia, pain and visual acuity 20/25.

She was interned at the infectious - parasitic disease sector, where she started a systemic endovenous antibiotic therapy ( Ceftriaxone 2g 12/12hs IV; Oxacilina 1g 12/12hs IV; Metronidazol 500mg 6/6hs IV). A CT showed ethmoidal sinusitis associated with left superior subperiostal nasal orbital abscess and a small nasal abscess at the right orbit ( Figure 1 ).

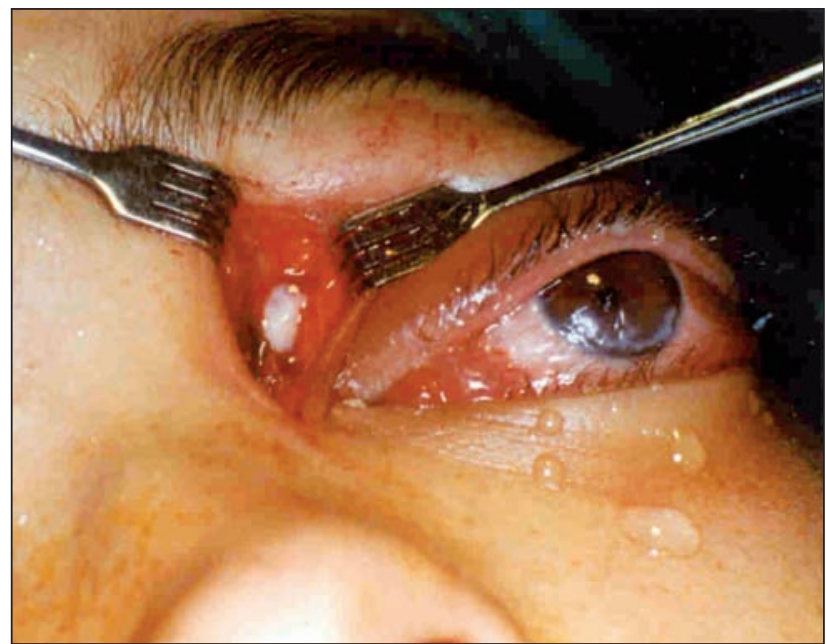

Figure 2: Pre-operatory aspect showing intense proptosis of OE and incisional draining of purulence secretion

After Five days of endovenous anti-microbial therapy, the clinical picture worsened with reduction of visual acuity in OE for hand movements, afferent pupilar defect in OE and total block up in the eye movements ( Figure 2). The patient was addressed to the oculoplastic, lachrymal pathways and orbit sector, where urgent surgical intervention was indicated with draining procedures of the abscess through the supeior nasal skin pathway ( Linch's incision ) ${ }^{(4)}$, associated to the endonasal pathway ( Figure 3 ).

Already at the inter-operatory stage, the patient showed an immediate improvement of the porptosis, and a penrose drain was left between the subperiostal space and the ipsilateral nasal cavity. The drained material was not examined due to the microbiological tests not available in the time os surgery. In the second postoperatory Day, improvements of ophthalmologic and general clinical picture were observed. In relation to the non-operated eye, only the clinical treatment showed complete remission of signals and symptoms.

In the $15^{\text {th }}$ day, the eye movements and photomotor reflexes were established, and the visual acuity in OE improved to 20/30 ( Figure 4 ).

The control CT demonstratred absence of the previously described tomographic result ( Figure 5 ).

\section{Discussion}

The moment for indication of surgical draining or only keeping a clinical therapy is controversial. The decision is based on the response to the conventional therapy ${ }^{(2)}$.The surgical drainig is not necessary for those patients Who show improvement of clinical signals. We 


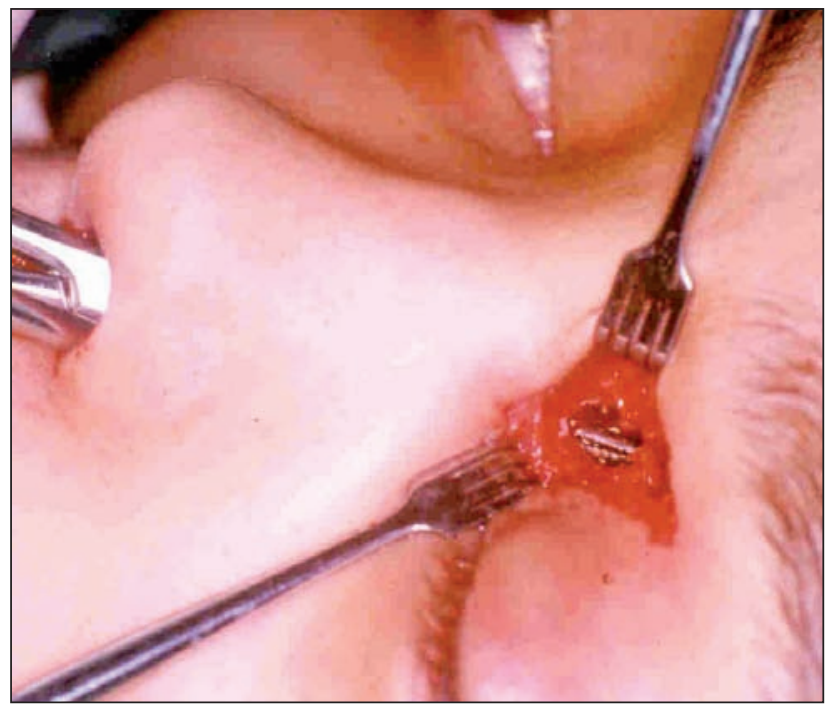

Figure 3: Pre-operatory after total draining. Surgical instrument showing the communication between the orbital and nasal cavities

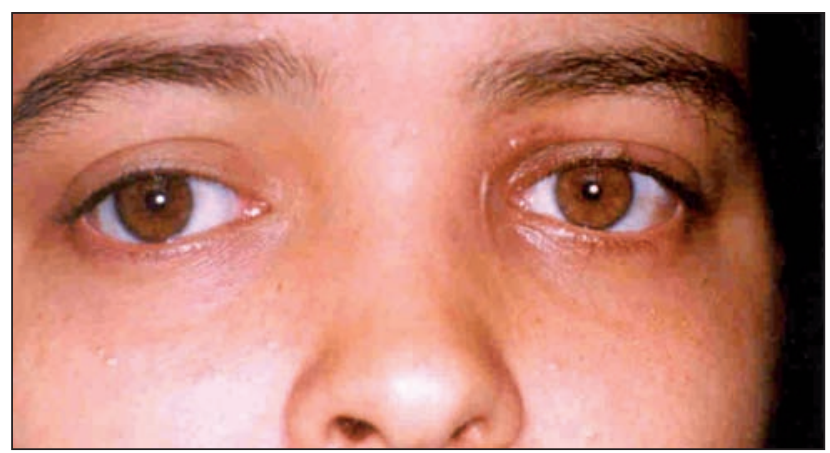

Figure 5: Final healing aspect

must emphasize that the abscess presence at $\mathrm{CT}$ by itself does not indicate surgery $(1,2)$, since not always what is seen as na abscess in TC can be surgically confirmed (4).

In spite of an adequate treatment, some complications may occur. In general, they are due to dissemination of the infectious process to adjacent structure. Among them, we can mention ocular complications, such as exposure ceratifis, optic neuritis, ocular hypertension and intracranial complications, as menigitis, thrombosis of the cavernous sinus, formsof cerebral abscess and finally death (5).

The surgical grainig is required when, besides orbital abscess, important drop is observed in $\mathrm{AV}$, as well as signs of neurological deterioration, such as afferent pupilary defect.

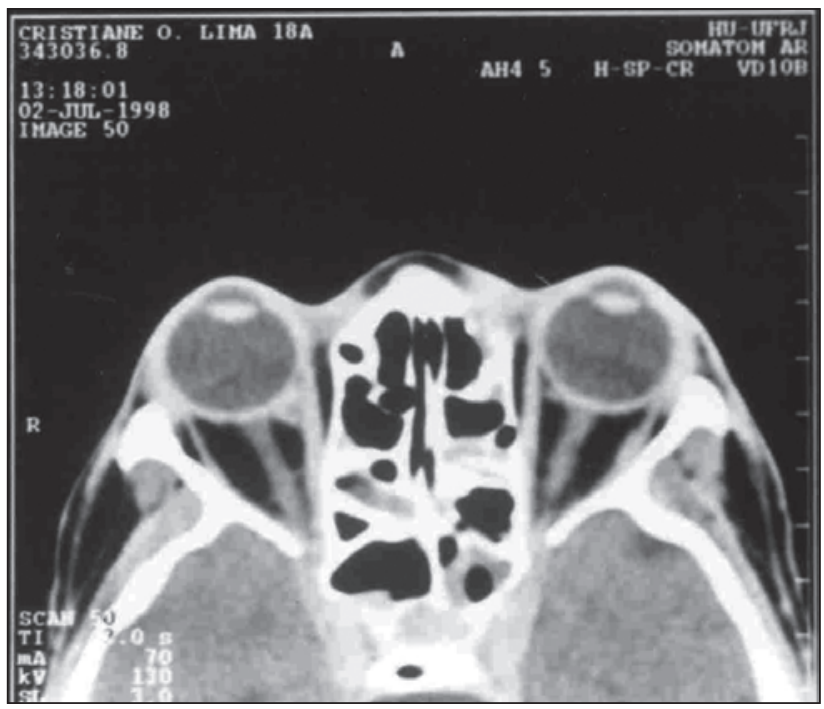

Figure 4: Orbital CT, axial cut; retarded post-operatory. Lacking abscess bilaterally

\section{REFERENCES}

1. Martin Hirsch DP, Habashi S, Hinton AH, Kotecha B: Orbital Cellulitis. Arch Emerg Med. 1992;9(2):143-8.

2. Goodwin WJ Jr, Weinshall M, Chandler Jr: The role os right resolution computerized tomography and standardized ultradound in the evaluation of orbital cellulitis. Laryngoscope (1982);92(7)1:729-31.

3. Angotti H, Resende DG, Barcelos SM, Massa H, Mendes JM, Hueb AE, Bottari CO. Celulite orbitária. Rev Bras Oftalmol. 1994;53(4):69-72.

4. Gold SC, Arrig PG, Hedges TR: 3D computerized tomography in the management of acute orbital cellulitis. Ophtalmic Surg (1987);18(10):753-6.

5. Rootman J, Stewart B, Goldberg RA. Regional approach to anterior, mid, and apical orbit. In: Rootman J, Stewart B, Goldberg RA. Orbital surgery. A conceptual approach. Philadelphia: Lippincott-Raven; 1995. p. 219-22.

Endereço para correspondência:

Abelardo de Souza Couto Júnior

Av. Nossa Senhora de Copacabana, 1120 - sl. 901

Copacabana

CEP 22060-000 - Rio de Janeiro (RJ), Brazil

E-mail: soluc@ig.com.br

Tel: (21) 2487-3476

José Fábio de Oliveira Miranda

R. Theodorico Fonseca,302 - Centro

CEP 27600-000 - Valença (RJ), Brazil

Tel: 24- 8115-2178

E-mail: Miranda_jfo@yahoo.com.br 